\title{
Monitoring activities of teenagers to comprehend their habits: study protocol for a mixed-methods cohort study
}

\author{
Mathieu Bélanger ${ }^{1,2,3^{*}}$, Isabelle Caissie ${ }^{1}$, Jacinthe Beauchamp ${ }^{1}$, Jennifer O'Loughlin ${ }^{4,5,6}$, Catherine Sabiston ${ }^{7}$ \\ and Michelina Mancuso ${ }^{8}$
}

\begin{abstract}
Background: Efforts to increase physical activity in youth need to consider which activities are most likely to be sustained over time in order to promote lifelong participation in physical activity. The Monitoring Activities of Teenagers to Comprehend their Habits (MATCH) study is a prospective cohort study that uses quantitative and qualitative methods to develop new knowledge on the sustainability of specific physical activities.

Methods/design: Eight hundred and forty-three grade 5 and 6 students recruited from 17 elementary schools in New Brunswick, Canada, are followed-up three times per year. At each survey cycle, participants complete self-report questionnaires in their classroom under the supervision of trained data collectors. A sub-sample of 24 physically active students is interviewed annually using a semi-structured interview protocol. Parents (or guardians) complete telephone administered questionnaires every two years, and a health and wellness school audit is completed for each school.

Discussion: MATCH will provide a description of the patterns of participation in specific physical activities in youth, and enable identification of the determinants of maintenance, decline, and uptake of participation in each activity. These data will inform the development of interventions that take into account which activities are the most likely to be maintained and why activities are maintained or dropped.
\end{abstract}

Keywords: Physical activity, Sport, Youth, Behavior, Adolescents, Mixed methods, Cohort

\section{Background}

In Canada, physical inactivity is the most prevalent preventable risk factor for chronic disease and mortality in youth and across the lifespan [1,2]. A recent objective assessment of physical activity in a representative sample of Canadians aged 6 to 19 years indicated that only 9\% of boys and $4 \%$ of girls engaged in the recommended 60 minutes of moderate-to-vigorous physical activity per day [3]. The burden of chronic disease will likely increase given that low levels of physical activity in youth is a strong predictor of a sedentary lifestyle in adulthood [4].

Physical inactivity in youth increases the risk of cardiovascular disease [5,6], diabetes [7], low bone mineral

\footnotetext{
* Correspondence: mathieu.f.belanger@usherbrooke.ca

${ }^{1}$ Centre de formation médicale du Nouveau-Brunswick, Pavillon

J.-Raymond-Frenette, 15, rue des Aboiteaux, Moncton, NB, Canada E1A 3E9

${ }^{2}$ Department of family medicine, Université de Sherbrooke, Sherbrooke,

Canada

Full list of author information is available at the end of the article
}

density [8,9], slower cognitive development [10-12], anxiety and depression [13], and obesity [14,15]. Physical activity and sports provide opportunities for developing competence, experiencing achievement, developing identities, forming positive relationships, learning to respect others, and enhancing a sense of community, while physical inactivity may result in suboptimal psychological and social growth [3]. Enrolment in physical activity programs is associated with improved social and communication skills, heighted motivation, lower rates of deviant behaviours, and better academic achievement [16].

Declines in physical activity during adolescence are characterized by marked changes in the range of physical activities in which youth engage [17]. The popularity of nearly all types of physical activity declines during adolescence [18] and the number of different activities in which adolescents engage also decreases with age $[17,19]$. With the possible exceptions of active transportation (i.e., 
walking, bicycling to and from school) and household chores, few young people maintain involvement in specific types of physical activity during adolescence [20-26].

Other reports indicate that the relative contribution of different types of physical activity changes with age. For example, although participation in both organized and non-organized physical activity decreases during adolescence [27-29], there are steeper declines in organized physical activity especially in girls [30]. Similarly, high drop-out rates from sports are reported from childhood to adolescence [18] and from adolescence to adulthood $[22,31,32]$. Some activities are engaged in almost exclusively by some age groups [31].Skipping rope, playing tag, and using playgrounds are popular among children $[24,25]$, whereas adults engage in physical conditioning and occupational physical activity [31]. Participation in specific physical activities in adulthood is nevertheless more likely among individuals who engaged in the activity during adolescence [22].

Systematic reviews have identified factors that are robustly associated with physical activity [33-35]. However, other than gender differences whereby boys prefer competitive sports $[20,21,36-38]$ and accumulate more vigorous physical activity than girls (who accumulate more moderate physical activity $[20,21]$ and prefer noncompetitive individual sports [37]), little is known about the determinants of participating in specific physical activities. Moreover, in-depth understanding of why adolescents discontinue, maintain or initiate physical activity participation is lacking.

Whereas qualitative studies provide rich descriptive information on how various factors influence behavioral patterns, few qualitative studies explore reasons for participation in physical activity during adolescence. Extant qualitative studies show that common reasons for taking part in physical activity include enjoyment, social interaction and weight management, whereas lacking confidence and ability are barriers [39-42]. A qualitative study that explored differences between physical activity maintainers and decliners [43] suggested that decliners reported negative social interactions, unsupportive social environments and feeling insufficiently competent as factors related to declines in physical activity. In contrast, maintenance of physical activity was associated with recognition of health benefits of physical activity, relatedness to others, and perceiving the environment as supportive of physical activity. Insights on factors explaining differences in patterns of physical activity participation during adolescence from both prospective qualitative and quantitative data are needed.

Monitoring Activities of Teenagers to Comprehend their Habits (MATCH) is a prospective mixed-methods study aimed at identifying and better understanding the determinants of discontinuing or sustaining participation in specific physical activities during adolescence. The objectives are: 1) to better understand the physical activityrelated experiences of participants in various types of physical activity, including individual activities, teambased activities, organised activities, and non-organised activities; 2) to develop better understanding of the process of maintaining adequate physical activity levels during the transition from childhood to adolescence; 3 ) to develop better understanding of the process of declining physical activity levels during the transition from childhood to adolescence; 4) to identify determinants of maintaining, discontinuing, or taking up participation in different types of physical activity from childhood to adolescence; and 5) to assess how changes in correlates relate to changes in participation in different types of physical activity.

\section{Methods/design}

\section{Design and conceptual framework}

MATCH is a prospective cohort study that uses quantitative and qualitative methods to develop new knowledge on the natural course and determinants of physical activity in youth. The MATCH study is grounded in the Self-Determination Theory (SDT) which enables better understanding of what motivates people to engage in, and maintain, certain types of physical activity. This in turn will help inform the design of interventions tailored to individual needs. SDT is founded on the notion that individuals behave according to interactions between extrinsic forces, intrinsic motives and essential needs [44]. An integral component of SDT is the underlying theory of Basic Psychological Needs, which assumes that a person maintains optimal functioning in contexts that support three basic psychological needs: competence, autonomy and relatedness $[45,46]$. Specifically, maintenance of participation in a physical activity is achieved when an individual feels that he or she masters the activity (competence), when the activity is undertaken by choice (autonomy), and when a meaningful connection is established with people through participation in the activity (relatedness). Chaos Theory is also incorporated in components of MATCH because random external events (i.e., loss of a friend, a public announcement, a conversation) may trigger at least short-term behavior change [47]. Chaos Theory supports investigating the influence of unplanned or uncontrolled factors that lead to sudden changes in physical activity. MATCH received Ethics Approval from the Comité d'Éthique de la Recherche $d u$ Centre Hospitalier de l'Université de Sherbrooke.

\section{Study population}

Nineteen schools were initially recruited from across the province of New Brunswick, Canada to participate in MATCH. However two schools were subsequently 
excluded because of a low return rate of consent forms. Schools recruited were selected to include a mix of French and English language schools from high, moderate, and low socioeconomic neighbourhoods, situated in rural and urban areas. Students were recruited within the 17 study schools from September 2011 to January 2012. Information packages were sent to the parents of all children in Grade 5 and 6 (10-12 years old), which provided detailed information on the MATCH study objectives and methods, as well as a consent form for parents and students to complete and return to the school. A total of 802 eligible students were recruited in the first year of data collection, for a response proportion of 51\%.

Contact information for parents or guardians of 490 of these 802 participants were obtained from schools. At least three attempts to contact each parent were made between August 2012 and February 2013. A total of 253 parents were contacted, of whom 246 (97\%) agreed to respond to a telephone-administered questionnaire.

For the qualitative component of the study, a purposelyselected sample of participants was selected from among those categorized, after four survey cycles, as most physically active (we ascertained that four questionnaires were needed to appropriately assess types of activities usually practiced). Six participants were recruited to represent each of the following categories of physical activity participation: involved primarily in a) team activities; b) individual activities; c) organised activities; and d) non-organised activities, for a total of 12 boys and 12 girls. Although overlap occurs among the types of physical activity practiced by different groups, the decision to recruit based on this categorisation was motivated by the intention to include participants with a wide variety of behavioral patterns and not to obtain four mutually exclusive groups. This way, we maximize our ability to develop an understanding of experiences of participation in different types of physical activities.

\section{Quantitative data collection}

Participants provide data three times each year until the end of grade 12 when they graduate from high school, for a total of up to 24 survey cycles per participant. Three survey cycles per year permit investigation of seasonal variation in activity levels and types of activity practiced [48]. At each survey cycle, participants complete self-report questionnaires in their classroom under the supervision of trained data collectors. Classroom visits in the first survey cycle took approximately 45-60 minutes and subsequent visits take approximately 20-30 minutes (students need less instructions). All data collection visits are scheduled at the convenience of teachers.

Data are collected from parents (or guardians) every two years a telephone-administered questionnaires.
During the first year that schools participate in the study, a designated person within each school completes a questionnaire in consultation with other staff, which collects data on the school environment. Responses are verified on-site by a research assistant.

\section{Student questionnaire}

The student questionnaire uses a checklist of 36 activities to collect data on the types of physical activity in which participants engaged over the past four months. The checklist incorporates all of the commonly practiced activities by youth in this region [49] and all activities included in other similar and validated physical activity checklists [50-52]. Participants report the frequency of participation in each activity, where the activity took place (school, home or neighborhood, indoor arena or gym, outdoor field, other), and with whom (by myself, organized group or team, siblings, friends, parents) activities were engaged in [24]. Pilot-testing of the questionnaire in English and French followed by discussions with 12 Grade 5 and 6 students indicated that children have no difficulty understanding and answering the questions.

Physical activity level is estimated using a simple 2item questionnaire developed for use among youth [53]. This questionnaire has demonstrated test-retest reliability $(r=0.77)$ and it correlated significantly with accelerometer data $(r=0.40$; this criterion validity index is as good as or better than other physical activity questionnaires) [53].

Basic Psychological Needs are measured in three questionnaires: (i) perceived competence is assessed with the 6-item subscale from the Intrinsic Motivation Inventory [54], (ii) perceived autonomy is assessed in the seven items from the autonomy subscale of the Basic Psychological Needs in Life Scale $[55,56]$, and (iii) perceived relatedness is assessed with the Relatedness to Others in Physical Activity Scale [57]. Each of these scales has internal consistency reliability coefficients (Cronbach's alpha) of 0.70 to 0.92 and is associated with physical activity [54-57]. Motives for physical activity is measured with the Motivations for Physical Activities MeasureRevised, a 30-item questionnaire that reflects five general motives for physical activity participation including enjoyment, competence, appearance, fitness and social interaction [58]. Enjoyment and competence are measures of intrinsic motives, whereas appearance, fitness and social are indicators of extrinsic motives [58]. The questionnaire has been used successfully to document a relationship between different types of motives for physical activity and long-term adherence to two specific types of physical activity (Tae Kwon Do and Aerobics) [58].

Active transportation is determined by asking youth how they usually get to and from school (actively, 
inactively or mixed) [59]. The core questionnaire also collects data on age, sex, school-based physical activities [59], sedentary behaviors [60,61], perceived physical activity of others, weight regulating behaviors [62], sleep patterns [63], pubertal stage [64,65], and unplanned events that may have influenced physical activity participation such as parental divorce, sickness in the family, difficulties at school, etc. Data on dietary habits are collected once a year, using items from the 2010 National Youth Physical Activity and Nutrition survey [66].

\section{Parent questionnaire}

Parents provide data on their own level of participation in physical activity in a telephone-administered questionnaire [67]. They also report on their participation in specific physical activities [67], and they provide data on family structure, socioeconomic level, and neighbourhood attributes [68].

Student and parent questionnaires were developed in English and translated into French if validated translations were not already available. The translation was undertaken by a bilingual kinesiologist whose mother tongue is French, with emphasis on conceptual rather than literal translations, and on clear and concise formulation. Three bilingual research team members reviewed and edited the translation for consistency with the English version. The French items were then back-translated by an independent individual whose mother tongue is English. The initial and final English versions where then compared to confirm consistency.

\section{School questionnaire}

The school questionnaire includes data on facilities available for physical activity inside schools, school yards and in the school neighborhood. Data are also collected on whether students have access to schools facilities during non-instructional times throughout the school day, if activities are offered to them when they remain indoors due to inclement weather during non-instructional time, and if students have access to school facilities outside school hours. We also collect information on frequency and duration of Physical Education classes, and school policies related to physical activity and nutrition (adapted from [69] and [70]). Data collected in this school questionnaire has a high level of validity (\% agreement with consensus-based opinion among school staff is perfect for $>75$ of items), test-retest reliability (exact agreement for $79.4 \%$ of items), and inter-judge reliability (77.3\% of items have shown exact agreement between raters) [71].

\section{Qualitative data collection}

The annual individual qualitative interviews with a subsample of 24 participants take place in a private room provided by schools. A phenomenological approach, which is particularly useful for understanding experiences of individuals and gaining insight into their motivations and actions, is used in the qualitative component of this study [72]. The phenomena under study include participation in specific types of physical activity, maintenance of physical activity, and decline in level of physical activity. Consistent with standard phenomenological methodology, our design involves multiple face-to-face interviews [73,74]. Participants are interviewed individually on a yearly basis to describe the evolution of their physical activity-related experiences as it relates to i) the type of physical activity they take part into as well as ii) maintenance or decline in participation in physical activity. The first interview serves as a baseline from which individual profiles will thereafter be built using data from follow up interviews. The interviews are audiorecorded and transcribed verbatim.

Although phenomenological research often begins from a perspective free from hypotheses or preconceptions [75], more recent viewpoints suggest that it is impossible to begin without preconceptions or bias and therefore emphasize that researchers should state their initial theoretical basis [76,77]. Therefore, the semistructured interview guide (used as a flexible template rather than a rigid list of questions [78]) aims at gathering data on participants' general experiences with physical activity and physical activity-related feelings of competence, relatedness with others, and autonomy (Basic Psychological Needs component of the SDT). Interviewers are also trained to examine the occurrence of random external triggers if marked changes in patterns of physical activity are noted.

In addition to the 24 participants above, we will invite participants with low physical activity in the first two years of study who subsequently become physically active for interviews that explore circumstances that led to this (sudden) change. Participants in these interviews will be met only once. These interviews could take place in year 3-6, depending on when sudden increases are noted. This will be of particular use to investigate the extent to which "chaotic events" influence increases in physical activity. Interviews will continue until data saturation is reached. All interviews will be recorded and transcribed.

\section{Limitations}

The study schools for MATCH represent a convenience sample. However, the schools were selected specifically to represent a mix of schools from low, middle, and higher socioeconomic status in a variety of urban, suburban, and rural settings in French and English regions of New Brunswick. Further, it is unlikely that the determinants of the maintenance or discontinuation of physical activity differ markedly between youth populations in 
Canada. It is possible that repeated data collection using the same questionnaire could sensitize participants to motives for maintaining or not participating in physical activity. This is partly why (in addition to cost, feasibility, and seasonality) we limited data collection to every $4^{\text {th }}$ month, rather than monthly or more frequently. Given the young age of participants, it is also possible that they experience difficulty expressing their feelings during the qualitative interviews. Our team includes researchers experienced in conducing in-depth interviews with this age group and has developed strategies to ease this process.

\section{Discussion}

The MATCH study provides the infrastructure for a research program that will generate better understanding of how physical activity participation evolves during childhood and adolescence. Recruiting grade 5 and 6 students and following them throughout adolescence is motivated by the finding that, for most people, peak physical activity level occurs between grade 5-7 [79], and then declines markedly from grade 8-11 [20,21,80-82]. The MATCH study will provide a detailed assessment of the natural history of physical activity participation in a period characterised by important changes in behaviour, growth, and puberty. No study has yet provided such detailed prospective data. Moreover, although the determinants of youth engaging in specific types of physical activities may vary, few investigations distinguish between types of physical activity. MATCH will enable investigating processes of sustaining, interrupting, or initiating participation in a wide variety of different physical activities. Particularly, although some studies have shown strong relationships between different types of physical activity motives and basic psychological needs and physical activity, MATCH has the capacity to tease out why such factors are important for some people, and if this changes over time and for different types of physical activities. In addition, the mixed methods approach enables investigation according to various theoretical frameworks. We will quantify the importance of several potential determinants of participation and develop in-depth understanding of how these determinants arise and co-occur. This combination of approaches will allow gaining insights into processes and events that lead to behavioural changes while also enabling unexpected questions to occur. All of this will guide the development of better interventions aimed at increasing and sustaining participation in physical activity among youth.

\section{Abbreviations}

SDT: Self-Determination Theory; MATCH: Monitoring Activities of Teenagers to Comprehend their Habits.
Competing interests

The authors declare that they have no competing interests.

\section{Authors' contributions}

MB conceptualized the study and its design. JB, JOL, MM and CS contributed to the conception of the study and study design. IC and MB organize and coordinate the data collection process. $\mathrm{MB}$ and $\mathrm{IC}$ drafted the first version of this manuscript. All authors reviewed the manuscript for intellectual content and approved it for publication.

\section{Acknowledgements}

The MATCH project is supported by the New Brunswick Health Research Foundation and by the Social Sciences and Humanities Research Council and Sport Canada through the joint Sport Participation Research Initiative. JOL holds a Canada Research Chair in the Early Determinants of Adult Chronic Disease.

\section{Author details}

${ }^{1}$ Centre de formation médicale du Nouveau-Brunswick, Pavillon J.-Raymond-Frenette, 15, rue des Aboiteaux, Moncton, NB, Canada E1A 3E9. 'Department of family medicine, Université de Sherbrooke, Sherbrooke, Canada. ${ }^{3}$ Research Centre, Vitalité Health Network, Moncton, Canada. ${ }^{4}$ Department of social and preventive medicine, Université de Montréal, Montreal, Canada. ${ }^{5}$ Centre de recherche du Centre Hospitalier de I'Université de Montréal, Montreal, Canada. ${ }^{6}$ Institut national de santé publique du Québec, Montreal, Canada. ${ }^{7}$ Faculty of Kinesiology and Physical Education, University of Toronto, Toronto, Canada. ${ }^{8} \mathrm{New}$ Brunswick Health Council, Moncton, Canada.

Received: 28 June 2013 Accepted: 8 July 2013

Published: 12 July 2013

\section{References}

1. Cameron C, Wolfe R, Craig C: Physical activity and sport: encouraging children to be active. Physical Activity Monitor. Ottawa, Canada: Canadian Fitness and Lifestyle Research Institute; 2005.

2. Canada S: Canadian Community Health Survey: A first look. Ottawa, Canada: The Daily; 2002.

3. Colley RC, Garriguet D, Janssen I, Craig CL, Clarke J, Tremblay MS: Physical activity of Canadian children and youth: accelerometer results from the 2007 to 2009 Canadian Health Measures Survey. Health reports / Statistics Canada, Canadian Centre for Health Information 2011, 22:15-23.

4. Paavola M, Vartiainen E, Haukkala A: Smoking, alcohol use, and physical activity: a 13-year longitudinal study ranging from adolescence into adulthood. J Adolesc Health: official publication of the Society for Adolescent Medicine 2004, 35:238-244.

5. Saakslahti A, Numminen P, Varstala V, Helenius H, Tammi A, Viikari J, Valimaki I: Physical activity as a preventive measure for coronary heart disease risk factors in early childhood. Scand J Med Sci Sports 2004, 14:143-149.

6. Timmons BW, Naylor P-J, Pfeiffer KA: Physical activity for preschool children - how much and how? Applied Physiology. Nutr Metab 2007, 32:S122-S134.

7. Huang JS, Gottschalk M, Norman GJ, Calfas KJ, Sallis JF, Patrick K: Compliance with behavioral guidelines for diet, physical activity and sedentary behaviors is related to insulin resistance among overweight and obese youth. BMC Res Notes 2011, 4:29.

8. Janz KF, Burns TL, Torner JC, Levy SM, Paulos R, Willing MC, Warren JJ: Physical activity and bone measures in young children: the lowa bone development study. Pediatrics 2001, 107:1387-1393.

9. Specker B, Binkley T: Randomized trial of physical activity and calcium supplementation on bone mineral content in 3- to 5-year-old children. $J$ Bone Miner Res: the official journal of the American Society for Bone and Mineral Research 2003, 18:885-892.

10. Son S-H, Meisels SJ: The relationship of young children's motor skills to later reading and math achievement. Merrill-Palmer Quarterly: Journal of Developmental Psychology 2006, 52:755-778.

11. Ginsburg KR, of Pediatrics Committee on Communications AA, of Pediatrics Committee on Psychosocial Aspects of Child AA, Health F: The importance of play in promoting healthy child development and maintaining strong parent-child bonds. Pediatrics 2007, 119:182-191. 
12. Burdette $H \mathrm{~L}$, Whitaker $\mathrm{RC}$ : Resurrecting free play in young children: looking beyond fitness and fatness to attention, affiliation, and affect. Arch Pediatr Adolesc Med 2005, 159:46-50

13. Calfas KJ, Taylor WC: Effects of Physical Activity on Psychological Variables in Adolescents. Pediatr Exerc Sci 1994, 6:406-423.

14. Klesges RC, Klesges LM, Eck LH, Shelton ML: A longitudinal analysis of accelerated weight gain in preschool children. Pediatrics 1995 95:126-130.

15. Moore LL, Nguyen US, Rothman K, Cupples LA, Ellison RC: Preschool physical activity level and change in body fatness in young children. The Framingham Children's Study. Am J Epidemiol 1995, 142:982-988.

16. Strong WB, Malina RM, Blimkie CJ, Daniels SR, Dishman RK, Gutin B, Hergenroeder AC, Must A, Nixon PA, Pivarnik JM, Rowland T, Trost S, Trudeau F: Evidence based physical activity for school-age youth. J Pediatr 2005, 146:732-7.

17. Aaron DJ, Storti KL, Robertson RJ, Kriska AM, Laporte RE: Longitudinal Study of the Number and Choice of Leisure Time Physical Activities From Mid to Late Adolescence. Arch Pediatr Adolesc Med 2002, 156:1075-1080.

18. Bélanger M, Gray-Donald K, O'Loughlin J, Paradis G, Hanley J: When Adolescents Drop the Ball: Sustainability of Physical Activity in Youth. Am J Prev Med 2009, 37:41-49.

19. Dovey SM, Reeder Al, Chalmers DJ: Continuity and change in sporting and leisure time physical activities during adolescence. Br J Sports Med 1998, 32:53-57.

20. Van Mechelen W, Twisk JWR, Post GB, Snel J, Kemper HCG: Physical Activity of Young People: The Amsterdam Longitudinal Growth and Health Study. Med Sci Sports Exerc 2000, 32:1610-1616.

21. Telama R, Yang X: Decline of Physical Activity from Youth to Young Adulthood in Finland. Med Sci Sports Exerc 2000, 32:1617-1622.

22. Kjonniksen $L$, Torsheim $T$, Wold B: Tracking of leisure-time physical activity during adolescence and young adulthood: a 10-year longitudinal study. Int J Behav Nutr Phys Act 2008, 5:69.

23. Stanley RM, Ridley K, Olds TS: The type and prevalence of activities performed by Australian children during the lunchtime and after school periods. J Sci Med Sport 2011, 14:227-232.

24. Pate RR, Sallis JF, Ward DS, Stevens J, Dowda M, Welk GJ, Young DR, Jobe JB, Strikmiller PK: Age-Related Changes in Types and Contexts of Physical Activity in Middle School Girls. Am J Prev Med 2010, 39:433-439.

25. Grieser M, Vu MB, Bedimo-Rung AL, Neumark-Sztainer D, Moody J, Young DR, Moe SG: Physical Activity Attitudes, Preferences, and Practices in African American, Hispanic, and Caucasian Girls. Health Educ Behav 2006, 33:40-51.

26. Erwin HE: Middle School Students' Leisure Activity Engagement: Implications for Park and Recreation Administrators. J Park and Recreation Adm 2008, 26:59-74

27. Wall MI, Carlson SA, Stein AD, Lee SM, Fulton JE: Trends by Age in Youth Physical Activity: Youth Media Campaign Longitudinal Survey. Med Sci Sports Exerc 2011, 43:2140-2147.

28. Duncan SC, Duncan TE, Strycker LA, Chaumeton NR: A Cohort-Sequential Latent Growth Model of Physical Activity from Ages 12-17 Years. Ann Behav Med 2007, 33:80-89.

29. Bélanger M, Gray-Donald K, O'Loughlin J, Paradis G, Hutcheon J, Maximova $\mathrm{K}$, Hanley J: Participation in organised sports does not slow declines in physical activity during adolescence. Int J Behav Nutr Phys Act 2009, 6:22.

30. Findlay L, Garner R, Kohen D: Patterns of Children's Participation in Unorganized Physical Activity. Res Q Exerc Sport 2010, 81:133.

31. Bélanger M, Townsend N, Foster C: Age-related differences in physical activity profiles of English adults. Prev Med 2011, 52:247-249.

32. Lunn PD: The sports and exercise life-course: A survival analysis of recall data from Ireland. Soc Sci Med 2010, 70:711-719.

33. Sallis JF, Prochaska JJ, Taylor WC: A review of correlates of physical activity of children and adolescents. Med Sci Sports Exerc 2000, 32:963-75.

34. Van Der HK, Paw MJ, Twisk JW, Van MW: A brief review on correlates of physical activity and sedentariness in youth. Med Sci Sports Exerc 2007, 39:1241-1250.

35. Lubans DR, Foster C, Biddle SJ: A review of mediators of behavior in interventions to promote physical activity among children and adolescents. Prev Med 2008, 47:463-470.

36. Vilhjalmsson R, Kristjansdottir G: Gender differences in physical activity in older children and adolescents: the central role of organized sport. Soc Sci Med 2003, 56:363-374.
37. Bradley CB, MCMurray RG, Harrell JS, Deng S: Changes in common activities of 3rd through 10th graders: the $\mathrm{CIHC}$ study. Med Sci Sports Exerc 2000, 32:1975-2153.

38. Nelson MC, Neumark-stzainer D, Hannan PJ, Sirard JR, Story M: Longitudinal and Secular Trends in Physical Activity and Sedentary Behavior During Adolescence. Pediatrics 2006, 118:1627-1634.

39. Allender S, Cowburn G, Foster C: Understanding participation in sport and physical activity among children and adults: a review of qualitative studies. Health Educ Res 2006, 21:826-835.

40. Bray SR, Born HA: Transition to university and vigorous physical activity: implications for health and psychological well-being. J Am College Health J of ACH 2004, 52:181-188.

41. Eime RM, Payne WR, Casey MM, Harvey JT: Transition in participation in sport and unstructured physical activity for rural living adolescent girls. Health Educ Res 2010, 25:282-293.

42. Coleman L, Cox L, Roker D: Girls and young women's participation in physical activity: psychological and social influences. Health Educ Res 2008, 23:633-647.

43. Bélanger $M$, Casey $M$, Cormier M, Filion AL, Martin G, Aubut S, Chouinard P, Savoie S-P, Beauchamp J: Maintenance and decline of physical activity during adolescence: insights from a qualitative study. Int J Behav Nutr Phys Act 2011, 8:117.

44. Teixeira P, Carraca E, Markland D, Silva M, Ryan R: Exercise, physical activity, and self-determination theory: a systematic review. Int J Behav Nutr Phys Act 2012, 9:78

45. Ryan $\mathrm{R}$, Deci E: Self-determination theory and the facilitation of intrinsic motivation, social development, and well-being. Am Psychol 2000, 55:68-78.

46. Ryan R: Deci, E: Self-determination theory: A macrotheory of human motivation, development, and health. Can Psychol 2008, 49:182-185.

47. Resnicow K, Page SE: Embracing chaos and complexity: a quantum change for public health. Am J Public Health 2008, 98:1382-9.

48. Belanger M, Gray-Donald K, O'Loughlin J, Paradis G, Hanley J: Influence of weather conditions and season on physical activity in adolescents. Ann Epidemiol 2009, 19:180-186.

49. Craig C, Cameron C, Russell S, Beaulieu A: Increasing Physical Activity Participation: Supporting Children's Participation. Ottawa, Ont: Canadian Fitness and Lifestyle Research Institute; 2001.

50. Sallis JF, Condon SA, Goggin KJ, Roby JJ, Kolody B, Alcaraz JE: The development of self-administered physical activity surveys for 4th grade students. Res Q Exerc Sport 1993, 64:32-38.

51. Crocker PRE, Bailey DA, Faulkner RA, Kowalski KC, McGrath R: Measuring general levels of physical activity: preliminary evidence for the Physical Activity Questionnaire for older children. Med Sci Sports Exerc 1997, 29:1344-1349.

52. Janz KF, Lutuchy EM, Wenthe P, Levy SM: Measuring Activity in Children and Adolescents Using Self-Report: PAQ-C and PAQ-A. Med Sci Sports Exerc 2008, 40:767-772

53. Prochaska JJ, Sallis JF, Long B: A physical activity screening measure for use with adolescents in primary care. Arch Pediatr Adolesc Med 2001, 155:554-559.

54. McAuley E, Duncan T, Tammen W: Psychometric properties of the Intrinsic Motivation Inventory in a competitive sport setting: a confirmatory factor analysis. Res Q Exerc Sport 1989, 60:48-58.

55. Gagné M: The role of autonomy support and autonomy orientation in prosocial behavior engagement. Motivation and Emotion 2003, 27:199-223.

56. Ntoumanis N: A Prospective Study of Participation in Optional School Physical Education Using a Self-Determination Theory Framework. J Educ Psychol 2005, 97:444-453.

57. Wilson PM, Bengoechea EG: The Relatedness to Others in Physical Activity Scale: Evidence for structural and criterion validity. J Appl Biobehav Res 2010, 15:61-87.

58. Ryan RM, Frederick CM, Lepes D, Rubio N, Sheldon KM: Intrinsic Motivation and Exercise Adherence. Int J Sport Psychol 1997, 28:335-354.

59. Wong SL, Leatherdale ST, Manske SR: Reliability and Validity of a SchoolBased Physical Activity Questionnaire. Med Sci Sports Exerc 2006, 38:1593-1600.

60. Schmitz KH, Harnack L, Jr DR J, Gao S, Lytle LA, Van Coevering P, Fulton JE: Reliability and Validity of a Brief Questionnaire to Assess Television Viewing and Computer Use. J Sch Health 2004, 74:370-377. 
61. Utter J, Neumark-Sztainer D, Jeffery R, Story M: Couch potatoes or french fries: are sedentary behaviors associated with body mass index, physical activity, and dietary behaviors among adolescents? J Am Diet Assoc 2003, 103:1298-1305.

62. Neumark-Sztainer D, Story M, Hannan PJ, Perry CL, Irving LM: Weight-related concerns and behaviors among overweight and nonoverweight adolescents: implications for preventing weight-related disorders. Arch Pediatr Adolesc Med 2002, 156:171-178.

63. Wolfson AR, Carskadon MA: Sleep schedules and daytime functioning in adolescents. Child Dev 1998, 69:875-887.

64. Petersen AC, Crockett L, Richards M, Boxer A: A self-report measure of pubertal status: Reliability, validity, and initial norms. J Youth Adolesc 1988, 17:117-133.

65. Carskadon MA, Acebo C: A self-administered rating scale for pubertal development. I Adolesc Health: official publication of the Society for Adolescent Medicine 1993, 14:190-195.

66. Park S, Blanck H, Sherry B, Brener N, OToole T: Factors associated with sugar-sweetened beverage intake among United States high school students. J Nutr 2012, 142:306-312.

67. Taylor H, Jacobs D, Schucker B, Knudsen J, Leon A, Debacker G: A questionnaire for the assessment of leisure time physical activities. J Chronic Dis 1978, 31:741-755.

68. Rosenberg D, Ding D, Sallis JF, Kerr J, Norman GJ, Durant N, Harris SK, Saelens BE: Neighborhood Environment Walkability Scale for Youth (NEWS-Y): reliability and relationship with physical activity. Prev Med 2009, 49:213-218.

69. Haug E, Torsheim T, Samdal O: Physical environmental characteristics and individual interests as correlates of physical activity in Norwegian secondary schools: the health behaviour in school-aged children study. Int J Behav Nutr Phys Act 2008, 5:47.

70. Beyers J, Vaillancourt J, Murkin E, Etches V, Kroeker C, Manske S, Leatherdale S, Sabiston C: In Development of the School Health Environment Survey (SHES). Edited by Centre for Behavioral Research and Program Evaluation Waterloo, Ontario: University of Waterloo; 2006.

71. Manske S: In Pilot Phase of the 2007-2008 School Health Environment Survey: Technical Report. Edited by Centre for Behavioral Research and Program Evaluation. Waterloo, Ontario: University of Waterloo; 2008.

72. Smith DW: Phenomenology. Fall 2011. Stanford, CA: Stanford Encyclopedia of Philosophy; 2011.

73. Benner P: Quality of life: a phenomenological perspective on explanation, prediction, and understanding in nursing science. ANS Adv Nurs Sci 1985, 8:1-14.

74. Poifroni E, W M: Perspective on Philosophy of Science in Nursing: An Historical and Contemporary Anthology. Washington: Lippincott.

75. Husserl E: Logical Investigations. New York: Humanities Press; 1970

76. Plummer K: Documents of Life: An Introduction to the Problems and Literature of a Humanistic Method. London: Unwin Hyman; 1983.

77. Stanley L, Wise S: Breaking Out Again : Feminist Ontology and Epistemology. London: Routledge; 1993:264.

78. Charmaz K: Constructing Grounded Theory: A Practical Guide Through Qualitative Analysis. Thousand Oaks, CA: Sage Publications; 2006.

79. Kahn JA, Huang B, Gillman MW, Field AE, Austin SB, Colditz GA, Frazier AL: Patterns and determinants of physical activity in U.S. adolescents. $J$ Adolesc Health: official publication of the Society for Adolescent Medicine 2008, 42:369-377.

80. Allison KR, Adlaf EM: Age and sex differences in physical inactivity among Ontario teenagers. Canadian J Public Health 1997, 88:177-180.

81. Allison KR, Adlaf EM, Dwyer JJ, Lysy DC, Irving HM: The decline in physical activity among adolescent students: a cross-national comparison. Canadian J Public health 2007, 98:97-100.

82. Caspersen CJ, Pereira MA, Curran KM: Changes in physical activity patterns in the United States, by sex and cross-sectional age. Med Sci Sports Exer 2000, 32:1601-1609.

\section{doi:10.1186/1471-2458-13-649}

Cite this article as: Bélanger et al:: Monitoring activities of teenagers to comprehend their habits: study protocol for a mixed-methods cohort study. BMC Public Health 2013 13:649. 